\title{
Second trimester maternal serum screening for fetal open neural tube defects and aneuploidy
}

Deborah A. Driscoll, MD, for the Professional Practice and Guidelines Committee

Key Words: neural tube defects, aneuploidy, MSAFP screening, multiple marker screening

Maternal serum screening has been modified during the past 25 years and is now widely utilized during the second trimester to identify women at risk for fetal open neural tube defects (ONTDs), anencephaly, and trisomies 21 and 18. This statement replaces the 1994 and 1996 ACMG position statements on serum screening and discusses clinical guidelines for screening that complement the sections of ACMG's Standards and Guidelines for Clinical Genetics Laboratories entitled "Prenatal screening for open neural tube defects" and "Prenatal screening for Down syndrome" (http://www.acmg.net).

\section{NEURAL TUBE DEFECTS}

In the 1980s, maternal serum screening programs became available to identify pregnancies at risk for ONTDs and anencephaly; $75 \%$ to $90 \%$ of ONTDs and $\geq 95 \%$ of anencephalics can be detected by elevated maternal serum alpha-fetoprotein (MSAFP) levels. MSAFP screening may also detect $85 \%$ of ventral wall defects. The optimal time for NTD screening is at 16 to 18 weeks gestation. Testing can be done between 15 and 20.9 weeks and the laboratory should be informed of the gestational age at the time the sample was drawn for an accurate interpretation. If there is a discrepancy in gestational age of 2 or more weeks after an ultrasound examination, then the test result must be reinterpreted. If the sample was drawn at less than 15 weeks, then a new sample should be sent with the accurate gestational age. Ultrasound dating of the pregnancy reduces the false-positive rate and increases the detection rate of ONTDs. The test is most accurate if the laboratory is also informed of maternal weight, race (Caucasian or Black/African American), presence of insulin-dependent diabetes, number

\footnotetext{
From the University of Pennsylvania Medical Center, Philadelphia, Pennsylvania.

Go to www.geneticsinmedicine.org for a printable copy of this document.

Disclaimer: This guideline is designed primarily as an educational resource for medical geneticists and other health care providers to help them provide quality medical genetic services. Adherence to this guideline does not necessarily assure a successful medical outcome. This guideline should not be considered inclusive of all proper procedures and tests or exclusive of other procedures and tests that are reasonably directed to obtaining the same results. In determining the propriety of any specific procedure or test, the geneticist should apply his or her own professional judgment to the specific clinical circumstances presented by the individual patient or specimen. It may be prudent, however, to document in the patient's record the rationale for any significant deviation from this guideline.

Approved by the Board of Directors July 10, 2004. Supercedes the statements entitled, "ACMG Position Statement on Multiple Marker Screening in Women 35 and Older” (1994), and "Statement on Multiple Marker Screening in Pregnant Women" (1996).
}

of fetuses, and family history of ONTD. These factors are used to adjust the multiples of the median (MoM) level. Cut-off levels for ONTD screening are 2.0 to $2.5 \mathrm{MoM}$ in singleton pregnancies, and 4.0 to $5.0 \mathrm{MoM}$ in twin pregnancies. Genetic counseling and additional testing such as targeted ultrasound examination and amniocentesis are recommended for pregnancies with an elevated MSAFP test result.

\section{TRISOMIES 21 AND 18}

Initially, MSAFP levels were used to modify a woman's risk for trisomy 21 based on age alone, and screening was offered to women less than 35 years of age who were not routinely offered genetic counseling and either amniocentesis or chorionic villus sampling (CVS). However, in women less than 35 years of age, the detection rate was low (15-20\%). Subsequently, human chorionic gonadotrophin (hCG) and unconjugated estriol (uE3) were added to the screening protocol to increase the detection rate of Down syndrome in pregnancy. Multiple marker screening (MMS) using three analytes (MSAFP, hCG, uE3) to adjust a woman's age-risk for Down syndrome raises the sensitivity to approximately $65 \%$. This is often referred to as the "triple test." Most recently, a fourth marker was added, dimeric inhibin-A (INH-A). This is referred to as the "quad or quadruple screen." Using a second trimester Down syndrome cut-off risk of 1 in 270, the combination of maternal age, MSAFP, hCG, uE3, and INH-A detects approximately $75 \%$ of Down syndrome cases in women who are younger than 35 years with a positive screening rate of $5 \%$, and over $80 \%$ of the Down syndrome fetuses in women 35 and older. In most cases of Down syndrome, the AFP and uE3 levels are lower, and hCG and INH-A levels are higher.

Serum screening using three of the analytes (AFP, hCG, $\mathrm{uE3}$ ) is able to identify women at risk for having a fetus with trisomy 18. In most cases of trisomy 18 , the levels are all low. The detection rate for trisomy 18 is at least $70 \%$.

The MMS does not detect other forms of aneuploidy such as trisomy 13 and Klinefelter syndrome $(47, \mathrm{XXY})$ that occur at a frequency of 1 in 20,000 and 1 in 1,000 livebirths, respectively, more often as a result of increasing maternal age. These would be detected on a routine cytogenetic analysis of cultured amniocytes or villi. Patients should be informed that the MMS is only a screening test for trisomies 21 and 18 and not a replacement for CVS or amniocentesis. Serum screening does reduce 
the number of invasive procedures performed, but will miss some affected pregnancies. Maternal serum screening in the second trimester has been validated and is an appropriate screening test for Down syndrome and trisomy 18. Patients who are screen positive for either trisomy 21 or 18 should be offered genetic counseling and amniocentesis.

The MMS test can be performed at 15 to 20 weeks of gestation. The laboratory must be informed of the gestational age at the time the sample was drawn for an accurate interpretation. The first day of the last menstrual period is the most common method for assessing gestational age, but ultrasound measurement of the crown-rump length in the first-trimester or a biparietal diameter (BPD) in the second trimester provides an accurate estimate of gestational age to within 7 and 10 days, respectively. If the gestational age changes by 2 or more weeks after an ultrasound examination, then the test results must be reinterpreted. If the sample was drawn at less than 15 weeks, then a new sample should be sent with the corrected gestational age.

Recent studies have shown the feasibility of first trimester screening for Down syndrome and trisomy 18 using the serum markers pregnancy-associated plasma protein A (PAPP-A), free beta subunit of hCG, and the sonographic measurement of nuchal translucency (NT), a fluid-filled space between the back of the fetal neck and the overlying skin. The detection rates are comparable to the quad screen in the second trimester, but provide women with the option of having an earlier test. First trimester screening requires appropriate ultrasound training and quality control before it can be implemented in routine practice. The Serum, Urine, and Ultrasound Screening Study (SURUSS) trial in the United Kingdom suggests that integrated screening (NT measurement and PAPP-A in the first trimester, combined with AFP, hCG, uE3, and INH-A in the second trimester) that yields one interpretation is the most sensitive and cost-effective test. Practice guidelines and laboratory standards for first trimester and integrated screening are being developed in the United States to assist with the implementation of these screening tests into clinical practice.

Genetic counseling and/or educational material should be available to patients to review the different screening tests that are available. Patients should be provided with information about Down syndrome, trisomy 18, and ONTDs, the benefits, risks and limitations of the tests, and the possible outcomes. Patients who have a positive second trimester screening test should be offered an amniocentesis.

\section{RECOMMENDATIONS}

The American College of Medical Genetics recommends the following: (1) Women should be offered MSAFP screening for the detection of ONTDs and anencephaly, optimally between 16 to 18 weeks gestation. (2) Women who have elected to have first trimester screening and/or CVS should be offered MSAFP screening, optimally between 16 to 18 weeks gestation. (3) Multiple marker screening (AFP, hCG, uE3 with or without INH-A) should be offered to women unless an amniocentesis is indicated based on their history and/or age, or they have elected to have first trimester screening and/or CVS. (4) CVS and amniocentesis should continue to be offered to women 35 years and older for the diagnosis of aneuploidy. (5) Women should be adequately counseled regarding the advantages and limitations of the screening tests and the availability of prenatal diagnostic tests.

\section{References}

1. Benn PA, Fang M, Egan JF, Horne D, Collins R. Incorporation of inhibin-A in second-trimester screening for Down syndrome. Obstet Gynecol 2003;101:451-454.

2. De Biasio P, Siccardi M, Volpe G, Famularo L, Snati F, Canini S. First-trimester screening for Down's syndrome using nuchal translucency measurement with free $\beta$-hCG and PAPP-A between 10 and 13 weeks of pregnancy: the combined test. Prenat Diagn 1999;19:360-363.

3. Haddow JE, Palomaki GE, Knight GJ, Williams J, Miller WA, Johnson A. Screening of maternal serum for fetal Down's syndrome in the first trimester. $N$ Engl J Med 1998;338:955-961.

4. Haddow JE, Palomaki GE, Knight GJ, Williams J, Pulkkinen A, Canick JA et al. Prenatal screening for Down's syndrome with use of maternal serum markers. N Engl J Med 1992;327:588-593.

5. Krantz DA, Larsen JW, Buchanan PD, Macri JN. First-trimester Down syndrome screening: free beta-human chorionic gonadotropin and pregnancy-associated plasma protein A. Am J Obstet Gynecol 1996;174:612-616.

6. Malone FD, Dalton ME. First-trimester sonographic screening for Down syndrome. Obstet Gynecol 2003;102:1066-1079.

7. Committee on Educational Bulletins of the American College of Obstetricians and Gynecologists. Maternal Serum Screening. ACOG Edu Bul No. 228 1996;55:299-308.

8. Orlandi F, Damiani G, Hallahan TW, Krantz DA, Macri JN. First-trimester screening for fetal aneuploidy: biochemistry and nuchal translucency. Ultrasound Obstet Gynecol 1997;10:381-386.

9. Wald NJ, Cuckle HS, Brock JH, Peto R, Polani PE, Woodford FP. Maternal serum alpha-fetoprotein measurement in antenatal screening for anencephaly and spina bifida in early pregnancy. Report of the U.K. Collaborative Study on Alpha-fetoprotein in relation to neural tube defects. Lancet 1977;1:1323-1332.

10. Wald NJ, Hackshaw AK. Combining ultrasound and biochemistry in first-trimester screening for Down's syndrome. Prenat Diagn 1997;17:821-829.

11. Wald NJ, Watt HC, Hackshaw AK. Integrated screening for Down's syndrome based on tests performed during the first and second trimester. N Engl J Med 1999;341: 461-467.

12. Wald NJ, Rodeck C, Hackshaw AK, Wlaters J, Chity L, Mackinson AM. SURUSS Research Group. First and second trimester antenatal screening for Down's syndrome: the results of the Serum, Urine and Ultrasound Screening Study (SURUSS). Health Technol Assess 2003;7:1-77.

13. Wapner R, Thom E, Simpson JL, Pergament E, Silver R, Filkins K et al. First-trimester screening for trisomies 21 and 18. N Eng J Med 2003;349:1405-1413. 